\title{
Diagnosis of Abdominal Hydatid Cyst Disease: The Role of Ultrasound and Ultrasound-Guided Fine Needle Aspiration Cytology
}

\author{
Tareq Sinan ${ }^{a}$ Mehraj Sheikh ${ }^{a}$ Fayaz A. Chisti e Osama Al Saeed ${ }^{a}$ \\ Zafar Sheikhd $^{d}$ P.R. Hirab Abdullah Behbehanic \\ Departments of aRadiology, bMicrobiology and cSurgery, Faculty of Medicine, Kuwait University, and \\ dMubarak Al-Kabeer Hospital, J abriya, and eDepartment of Radiology, Amiri Hospital, Kuwait, Kuwait
}

\section{Key Words}

Ultrasound · Fine needle aspiration cytology · Hydatid cyst disease

\begin{abstract}
Objective: To retrospectively analyze the role of ultrasound (US) imaging and US-guided fine needle aspiration cytology in the diagnosis and management of abdominal hydatid cyst disease (HCD). Subjects and Methods: The medical records of 55 diagnosed cases of HCD seen between J anuary 1986 and December 2000 at Mubarak Al-Kabeer Hospital and Al-Amiri Hospital in Kuwait were reviewed for demographic and clinical data, including radiology and serology. The US findings of the patients were classified into four types as follows: type I: single or multiple well-defined cysts, with or without detached or collapsed wall and with or without echogenic contents; type II: single or multiple cysts with peripheral cysts, with or without echogenic contents; type III: solid or semisolid lesions, and type IV: cysts with calcified walls. Results: The overall accuracy of US in the diagnosis of HCD was $80 \%$ (44/55 cases). US examination was suggestive of HCD type I, 16/19 (84\%), type II, 21/23 (91\%), type III, 3/8 (38\%), and type IV , 4/5 (80\%). For the
\end{abstract}

\section{KARGER}

Fax +41613061234

E-Mail karger@karger.ch

www. karger.com
(C) 2002 S. Karger AG, Basel

1011-7571/02/0114-0190\$18.50/0

Accessible online at:

www. karger.com/mpp
11 remaining undiagnosed cases, US was useful for localizing the lesions for US-guided fine needle aspiration cytology. It established the diagnosis in all the 11 cases, without precipitating complications. Conclusion: US alone was valuable for diagnosing and localizing HCD in the abdomen except for solid-type lesions. USguided fine needle aspiration cytology was useful in localizing and establishing the diagnosis of HCD in the cases where US alone was ineffective.

Copyright @2002 S. Karger AG, Basel

\section{Introduction}

Hydatid cyst disease (HCD) is an infection of humans caused by the larval stage of the dog tapeworm Echinococcus granulosus. The infection is commonly caused by $E$. granulosus, resulting in unilocular cysts, or by Echinococcus multilocularis, resulting in the relatively rare multilocular cystic alveolar form of the disease [1]. Humans are infested either by direct contact with definitive hosts or indirectly by ingestion of eggs due to contaminated water and food sources [2, 3].

$\mathrm{HCD}$ is endemic in several parts of the world, especially in the Middle East, South America, New Zealand and

Dr. Mehraj Sheikh

Department of Radiology, Faculty of Medicine

Kuwait University, PO Box 24923

13110 Safat (Kuwait)

Fax+965 5330473, E-Mail mehraj@hsc.kuniv.edu.kw 
Australia, and with population migration and frequent travel, it is increasingly seen in nonendemic areas $[1,4,5]$. Though the abdomen, especially the liver, is the most common site, virtually any organ may be involved $[1,5$, 6]. The disease is often asymptomatic and is frequently diagnosed while patients are under investigation for some unrelated problems [7]. Furthermore, as a result of infection and/or rupture of hydatid cysts, symptoms and signs may mimic many disease processes, including malignancy [7].

Although definitive diagnosis of HCD may require a combination of clinical, radiological, serological and pathological findings, ultrasonography (US) in particular can be valuable in determining the diagnosis, localizing the cysts and assessing the cyst activity [4]. It is therefore necessary to be aware of the various sonographic appearances of the disease and have a high index of suspicion. In this study we review 55 cases of proven abdominal HCD diagnosed at Mubarak Al-Kabeer and Al-Amiri Hospitals, Kuwait, highlighting the role of US in the diagnosis of abdominal HCD.

\section{Subjects and Methods}

We retrospectively reviewed the records of 55 medical patients with a diagnosis of HCD. These patients, all of whom were adults, age 20-65 years (32 females and 23 males), had presented at Mubarak Al-Kabeer and Al-Amiri Hospitals, Kuwait, between 1986 and 2000. Anyone or a combination of techniques involving radiology, cytology, histopathology and serology was used to reach a diagnosis. Surgery was performed in 22 cases, for which information on treatment, complications and follow-up was available. The serological test given to 38 patients was indirect hemagglutination test (Cellognost Echinococcosis, Dude Behring, Marbury, Germany).

The radiological techniques included US and computed tomography. US was done on all the 55 patients. We calculated how many of the 55 cases were accurately diagnosed by US technique alone and by US-guided fine needle aspiration cytology (FNAC). We also classified the ultrasonic features into four types: type I: single or multiple well-defined unilocular cysts with or without detached or partially collapsed wall, with or without thick echogenic cyst content; type II: single or multiple multiseptated cysts or with peripheral daughter cysts, with or without thick echogenic material; type III: solid or semisolid lesions; type IV: calcified lesions, showing rim calcification or calcified spot in the cyst wall.

FNAC was performed in 23 cases, which included 11 patients who had preoperative aspiration done with US guidance and 12 who had peroperative smears prepared. For US-guided FNAC, the lesion in question was localized, and an appropriate and safe path to the lesion was identified. The guided needle (20-22 G) with stylet was introduced into the lesion under real-time US monitoring. The stylet was withdrawn and aspiration was done with suction using $20-\mathrm{cm}^{3}$ syringe with a pistol handle. The adequacy of the material was immediately confirmed by a cytologist with the help of a rapid diff quick
Table 1. Clinical features

\begin{tabular}{lcl}
\hline Presentation & \multicolumn{2}{l}{ Patients } \\
\cline { 2 - 3 } & $\mathrm{n}$ & $\%$ \\
\hline No symptoms & 19 & 34.54 \\
Nonspecific symptoms & 22 & 40 \\
$\quad$ Vague abdominal pain/abdominal fullness & 13 & \\
$\quad$ Right hypochondrium pain & 9 & \\
Abdominal mass & 9 & 16.36 \\
$\quad$ III-defined (not specified) & 6 & \\
$\quad$ Right hypochondrium & 2 & \\
$\quad$ Paraumbilical & 1 & \\
Fever & 5 & 9 \\
Jaundice & 2 & 3.63 \\
Acute abdominal pain & 2 & 3.63 \\
Shock & 1 & 1.18 \\
Hemoptysis & 1 & 1.81 \\
\end{tabular}

stain, and repeat aspiration was performed whenever the cytologist found insufficient material. Adequate numbers of smears were prepared for both Papanicolaou and diff quick stains. The criteria for diagnosis included hydatid membranes, protoscolices, scolices and hooklets.

\section{Results}

The clinical presentation of the patients, the majority of whom were either asymptomatic or presented with nonspecific symptoms is shown in table 1 . The diagnosis of Echinococcus in these patients was made while investigating the presenting problem. Two patients presenting with acute symptoms of an indeterminate nature (pain?) were found to have ruptured hydatid cysts. One of the patients went into shock and was resuscitated and operated on as an emergency.

The US images of the four HCD types are shown in figure 1-4. The US examination successfully diagnosed the disease in 44 out of 55 cases (80\%), as shown in table 2. US examination was suggestive of HCD type I, $16 / 19(84 \%)$, type II, $21 / 23(91 \%)$, type III, $3 / 8(38 \%)$, or type IV, 4/5 (80\%). US examination failed to suggest HCD in 11 cases: type I, 3/19 (16\%), type II, 2/23 (9\%), type III, $5 / 8(62 \%)$ and type IV, $1 / 5(20 \%)$.

US-guided FNAC was useful in establishing the diagnosis in all the 11 cases. The details of these patients are given in table 3 . Provisionally the diagnosis was not considered in any of these patients. There was no complication with US-guided FNAC or intraoperative cytology. The material obtained in all patients with US-guided 

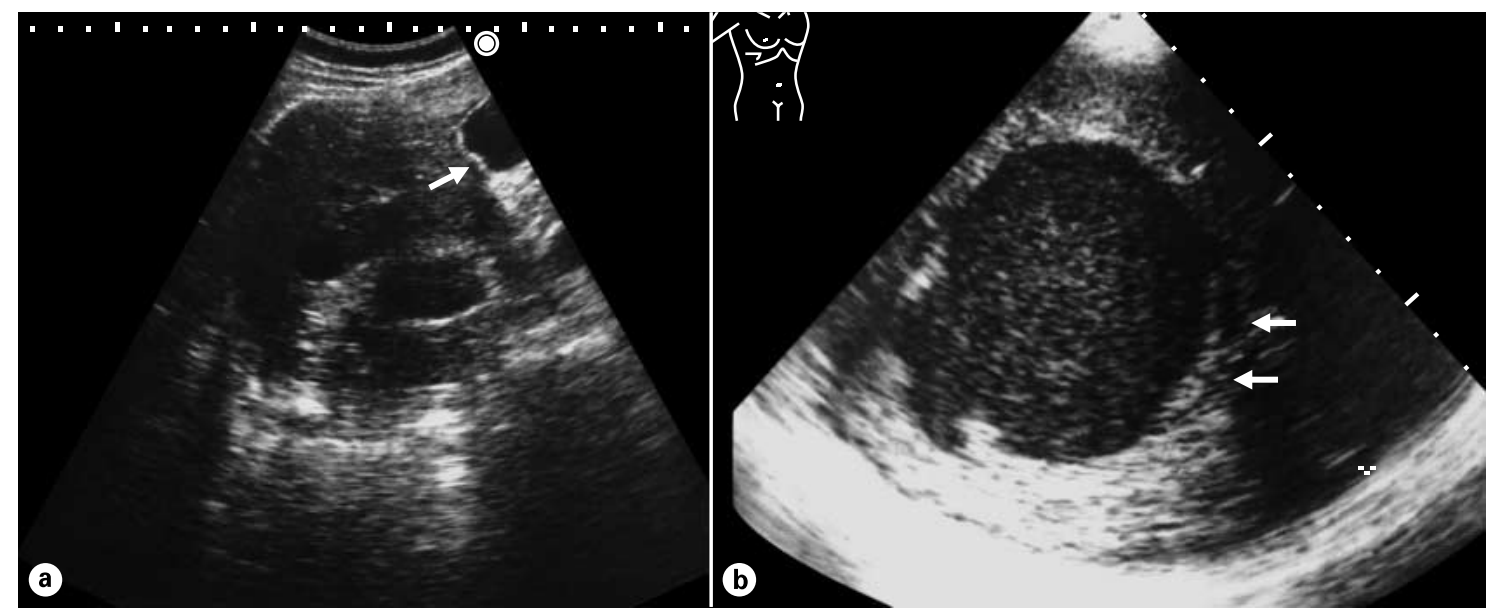

Fig. 1. Examples of type I cysts. a Multiple hydatid cyst in the liver resembling simple cysts. Note partially collapsed wall of one cyst (arrow). b Solitary cyst in the liver containing thick echogenic material (hydatid sand), resembling abscess. Note detached wall of the cyst (arrows).

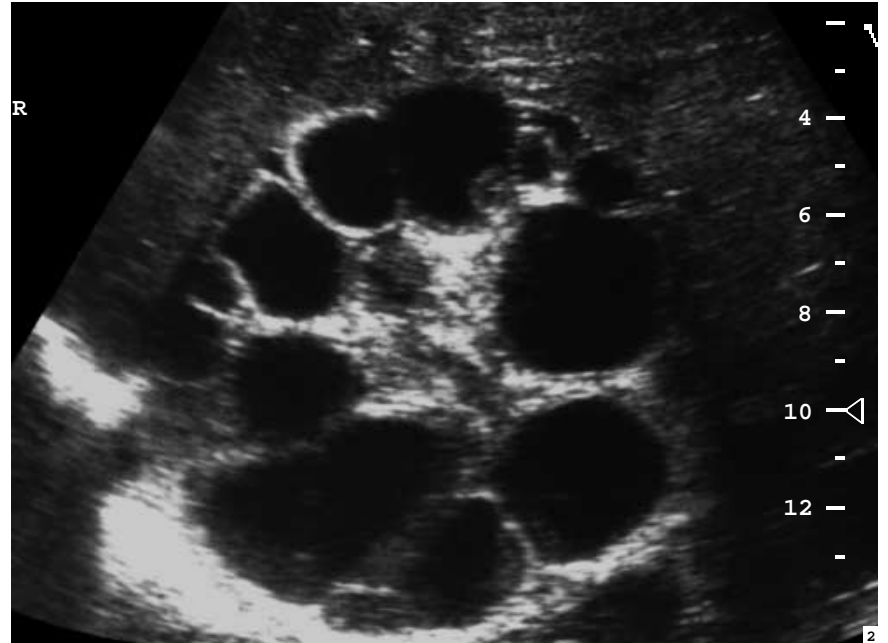

Fig. 2. Type II showing a large solitary cyst with peripheral cysts representing daughter cysts.

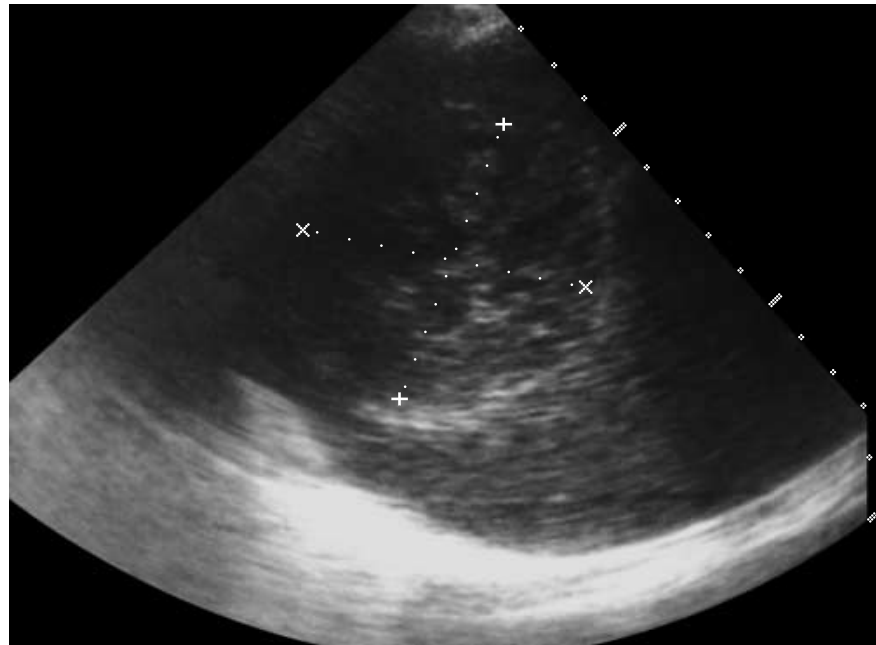

Fig. 3. Type III showing a large homogeneous lesion of the liver resembling a solid lesion.

Table 2. Types of sonographic features of HCD and clinico-radiological diagnosis

\begin{tabular}{llccc}
\hline Type & Sonographic features & \multicolumn{2}{l}{ US diagnosis } & \multirow{2}{*}{ Total } \\
\cline { 3 - 4 } & & suggestive & not suggestive & \\
\hline I & Unilocular, simple cysts \pm collapsed or detached wall \pm debris & $16(29 \%)$ & $3(5.5 \%)$ & $19(34.5 \%)$ \\
II & Multilocular or multicystated cysts \pm detached wall \pm debris & $21(38 \%)$ & $2(3.8 \%)$ & $23(41.8 \%)$ \\
III & Solid or semisolid appearance & $3(5.5 \%)$ & $5(9.0 \%)$ & $8(14.5 \%)$ \\
IV & Calcification & $4(7.3 \%)$ & $1(1.7 \%)$ & $5(9.0)$ \\
\hline Total & & $44(80 \%)$ & $11(20 \%)$ & $55(100 \%)$
\end{tabular}



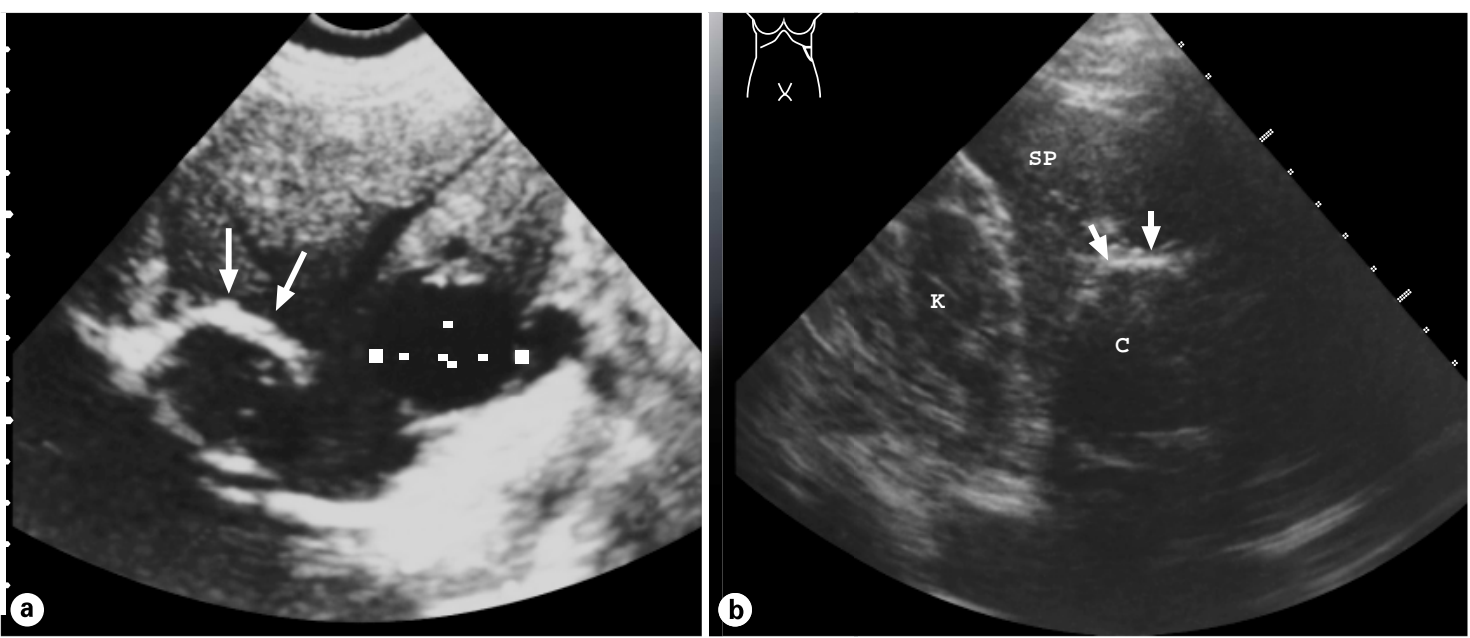

Fig. 4. Type IV showing a cyst with rim calcification in the liver (a) and spleen (b). In the liver a type I solitary cyst is also seen adjacent to the calcified cyst (calipers). $\mathrm{SP}=$ Spleen; $\mathrm{K}=$ upper pole of left kidney; $\mathrm{C}=$ cyst.

Table 3. Patients who had US-guided FNAC

\begin{tabular}{|c|c|c|c|c|}
\hline Case & Organ & $\begin{array}{l}\text { US } \\
\text { appearance }\end{array}$ & Clinical presentation & $\begin{array}{l}\text { Preaspiration } \\
\text { sonographic diagnosis }\end{array}$ \\
\hline 1 & Liver & III & known case of bowel cancer & metastasis \\
\hline 2 & Liver & III & mass in the lung on chest $\mathrm{X}$-ray, presumed cancer & metastasis \\
\hline 3 & Liver & III & right hypochondrium mass & malignant mass in the liver \\
\hline 4 & Liver & I & fever and right hypochondrial pain & abscess \\
\hline 5 & Liver & I & fever & abscess \\
\hline 6 & Liver & III & routine US scanning & ? malignancy \\
\hline 7 & Liver & I & multiple focal lesions in liver & ? metastasis \\
\hline 8 & Kidney & II & right flank fullness and dull aching & necrotic renal mass \\
\hline 9 & Retroperitoneum & II & pulsating mass in the abdomen & aortic aneurysm \\
\hline 10 & Abdominal wall & I & anterior abdominal wall cyst? Nature & right hypochondrial mass \\
\hline 11 & Back of the neck & III & neck swelling & lipoma \\
\hline
\end{tabular}

FNAC was diagnostic, while materials from 3 of the 12 patients intraoperatively was suggestive but not diagnostic, the latter showing only germinal membranes and inflammatory cells.

The cysts were localized mostly in the liver, the only organ involved in over half of the cases (table 3 ). Other organs involved included the spleen $(20 \%)$ and kidneys (7.27\%), but extraabdominal involvement was rare (table 4). Solitary cysts were found in 26 patients ( 24 were in the liver). Multiple cysts in a single organ were found in 15 cases, and multiple cysts in one or more organs were found in 14 cases.

Diagnosis of Abdominal Hydatid Cyst

Disease
The 22 patients who had surgery at Mubarak AlKabeer Hospital had removal of cysts in the liver and other organs where feasible. In 1 patient, there was wound and liver contamination with cyst contents during surgery, resulting in infection and delayed wound healing. This patient had a wound debridement done with removal of necrotic liver tissue. Another patient postoperatively developed a low leakage fistula that was excised. The patient with preoperative anaphylactic shock also had immediate postoperative shock and went into shock again on the 5th postoperative day. Subsequent follow-up of all the cases was otherwise uneventful.

Med Principles Pract 2002;11:190-195 
Table 4. Organs involved

\begin{tabular}{lcc}
\hline Organ & Number & Percentage \\
\hline Liver & 49 & 89.00 \\
Spleen & 11 & 20.00 \\
Kidneys & 4 & 7.27 \\
Lungs & 3 & 5.45 \\
Peritonium & 3 & 5.45 \\
Retroperitonium & 1 & 1.80 \\
Soft tissue & 2 & 3.63 \\
\hline
\end{tabular}

\section{Discussion}

Patients with abdominal HCD are usually asymptomatic, unless the cysts become complicated due to their massive size, rupture, or infection. The lack of symptoms is mainly attributed to the slow growth of the cysts - about $1 \mathrm{~mm}$ per month [5], resulting in a long delay before presentation. The asymptomatic cases are commonly diagnosed incidentally by routine radiological examination, especially in the course of investigating symptoms due to other illness [7]. Symptoms are usually nonspecific and are commonly related to pressure or location, consistent with the findings of this study (table 1).

Complications such as rupture may produce anaphylaxis [8-11] as a result of the release of cystic fluid antigen into circulation. Rupture into the peritoneal cavity may result in disseminated peritoneal hydatid disease $[9,12]$ and into the bronchus, hemoptysis [13]. As in our study, secondary bacterial infection of the cysts is not uncommon, and fungal infection of lung cysts in a nonimmunocompromised host has been reported [14]. Presence of cysts in the brain or in the spine may result in neurological symptoms [15-18]; in this study, 1 patient had a central abdominal mass that was initially diagnosed as an aortic aneurysm. In our study, 2 patients had ruptured cysts. Two other patients presented with fever and other related symptoms, suggesting a clinical diagnosis of liver abscess.

The diagnosis of hydatid cyst mainly depends upon clinical awareness, particularly in endemic areas. Although radiological features of hydatid cyst have been well characterized by various imaging modalities [7, 19], US is the examination of choice because of its high diagnostic accuracy, low cost and noninvasiveness [4, 20]. Sonography not only helps in diagnosis and localization of the cysts, but also in the assessment of the state and activity of the disease. Sonographic features showing multiloculated cysts representing unilocular cysts with detached membranes (type I) or daughter cysts (type II) are typical signs of hydatid cysts [4]. The well-defined unilocular cysts without detached walls are similar to any benign cyst, but considered hydatid in some endemic areas unless proved otherwise; more so if the cysts contain thick echogenic material representing hydatid 'sand' [4]. However, with relevant clinical features these cysts with thick matter or with solid appearance may mimic abscesses [4] or malignancy [20].

In our study, sonographic features of type I or type II and lesions with rim calcification are highly suggestive of the disease as described by others [4,20]. The cases that were undiagnosed by US were mainly the solid type (type III) and most of these were initially diagnosed as malignant lesions, consistent with previous reports [20]. The $E$. multilocularis type, which grows by exogenous proliferation and behaves like a malignant neoplasm [6], is known to cause such diagnostic difficulties.

FNAC has been established as a standard procedure for the pathologic diagnosis of a large variety of lesions in different locations; however, its utility in hydatid cysts has thus far been limited due to the fear of anaphylaxis and spread of disease. Nonetheless, some reports have shown it to be a relatively safe procedure for the diagnosis of hydatid cysts [22-24]. Von Sinner et al. [8], in a review of 40 studies of FNAC of the hydatid cyst involving 31 patients over a 15 -year period, recorded only 6 complications, of which only 1 patient had a severe anaphylactic reaction with a sudden drop in blood pressure and signs of shock. In the other 5 cases, only minor reactions characterized by rash and minor asthmatic attack were observed. Although these investigators encourage liberal use of FNAC for hydatid disease, they advocate taking precautions such as having anaphylactic medication readily available. However, Das et al. [22] did not report any complications after performing US-guided FNAC in 11 patients. Likewise, there were no complications in our study in which US-guided FNAC was performed on 11 HCD patients. There was probable spillage of cyst contents during surgical removal of the cyst in 1 case, resulting in an anaphylactic reaction and subsequent delay in wound healing and fistula formation.

\section{Conclusion}

US alone was valuable for diagnosing and localizing HCD in the abdomen except for solid-type lesions. For 11 cases where US alone was ineffective, US-guided FNAC was useful establishing the diagnosis. 


\section{References}

1 Dosan R, Yuksel M, Cetin G, Suzer K, Alp M, Kaya S, Unlu M, Moldibi B: Surgical treatment of hydatid cysts of the lung: Report of 1,055 patients. Thorax 1989;44:192-199.

2 Amr SS, Amr ZS, Jitawi S, Annab H: Hydatidosis in Jordan: An epidemiological study of 306 cases. Ann Trop Med Parasitol 1994;88: 623-627.

3 Beaver PC, Jung RC, Cupp EW: Clinical Parasitology, ed 9. 31:Philadelphia, Lea \& Febiger, 1984, pp 505-543.

4 Suwan Z: Sonographic findings in hydatid disease of the liver: Comparison with other imaging methods. Ann Trop Med Parasitol 1995;89: 261-269.

5 Sparks AK, Connor DH, Neafie RC: Echinococcosis; in Binford $\mathrm{CH}$, Connor $\mathrm{DH}$ (eds): Pathology of Tropical and Extraordinary Diseases. Washington, Armed Forces Institute of Pathology, 1976, pp 530-533.

6 Czermak BV, Unsinn KM, Gotwald T, Waldenberger P, Freund MC, Bale RJ, Vogel W, Jaschke WR: Echinococcus multilocularis revisited. AJR 2001;176:1207-1212.

7 von Sinner WN: New diagnostic signs in hydatid disease: Radiography, ultrasound, CT and MRI correlated to pathology. Eur J Radiol 1991;12:150-159.

8 von Sinner WN, Nyman R, Linjawi T, Ali AM: Fine needle aspiration biopsy of hydatid cysts. Acta Radiol 1995;36:168-172.
9 Agarwal PK, Husain N, Singh BN: Cytologic findings in aspirated hydatid fluid. Acta Cytol 1989;33:652-654.

10 Stampfel G: Anaphylactoid reaction: A rare complication after fine needle biopsy of the lungs. Radiologe 1982;22:329-330.

11 von Sinner WN: Ultrasound, CT and MRI of ruptured and disseminated hydatid cysts. Eur J Radiol 1990;11:31-37.

12 Pandolfo I, Scribano E, Lavagnini L, Termini $\mathrm{S}$, Longo M: Post-traumatic intraperitoneal dispersion of echinococcal disease. J Comput Assist Tomogr 1982;6:1034-1035.

13 Vera-Alvarez J, Marigil-Gomez M, AbascalAgorreta M: Echinococcus hooklets in the sputum: Sinus tract extension of a liver cyst to lung. Acta Cytol 1995;39:1187-1189.

14 Kini U: Invasive mycosis of a pulmonary hydatid cyst in a non-immunocompromised host. $\mathbf{J}$ Trop Med Hyg 1995;98:404-406.

15 Altinors N, Senveli E, Donmez T, Bavbek M, Kars Z, Sanli M: Management of problematic intracranial hydatid cysts. Infection 1995;23: 283-287.

16 Krajewski R, Stelmasiak Z: Cerebral hydatid cyst in children. Childs Nerv Syst 1991;7:154155.
17 Kars HZ, Hekimoglu B, Cepoglu C: Spinal epidural hydatid cyst: Radiological and ultrasonographical workup of a case. Eur J Radiol 1990; 11:212-214.

18 Sheikh M, Osman M: Spinal extradural hydatis cyst. Med Principles Pract 1998;30:150-152.

19 Singh S, Gibikote SV: Magnetic resonance imaging signal characteristics in hydatid cysts. Australas Radiol 2001;45:128-133.

20 Caremani M, Benci A, Maestrini R, Accorsi A, Caremani D, Lapini L: Ultrasound imaging in cystic echinococcosis proposal of a new sonographic classification. Acta Trop 1997;67:91105.

21 Chemtal AK, Bowry TR, Ahmad Z: Evaluation of five immunodiagnostic techniques in echinococcus patients. Bull World Health Organ 1981;59:767-772.

22 Das DK, Bhambhani S, Pant CS: Ultrasound guided fine-needle aspiration cytology: Diagnosis of hydatid disease of the abdomen and thorax. Diagn Cytopathol 1995;12:173-176.

23 Hira PR, Shweiki H, Lindberg LG, Shaheen Y, Francis I, Leven H, Behbehani K: Diagnosis of cystic hydatid disease: Role of aspiration cytology. Lancet 1988;ii:655-657.

24 Bret PM, Fond A, Bretagnolle M, Valette PJ, Thiesse P, Lambert R, Labadie M: Percutaneous aspiration and drainage of hydatid cysts in the liver. Radiology 1988;168:617-620. 